$10 / 9.142850$

SANDIA REPORT

SAND90-0351 - UC-706

Unlimited Release

Printed July 1992

\title{
Lightning Threat Warning System at the Tonopah Test Range
}

Roger Smith

Prepared by

Sandia National Laboratories

Albuquerque, New Mexico 87185 and Livermore, California 94550

for the United States Department of Energy

under Contract DE-AC04-76DP00789
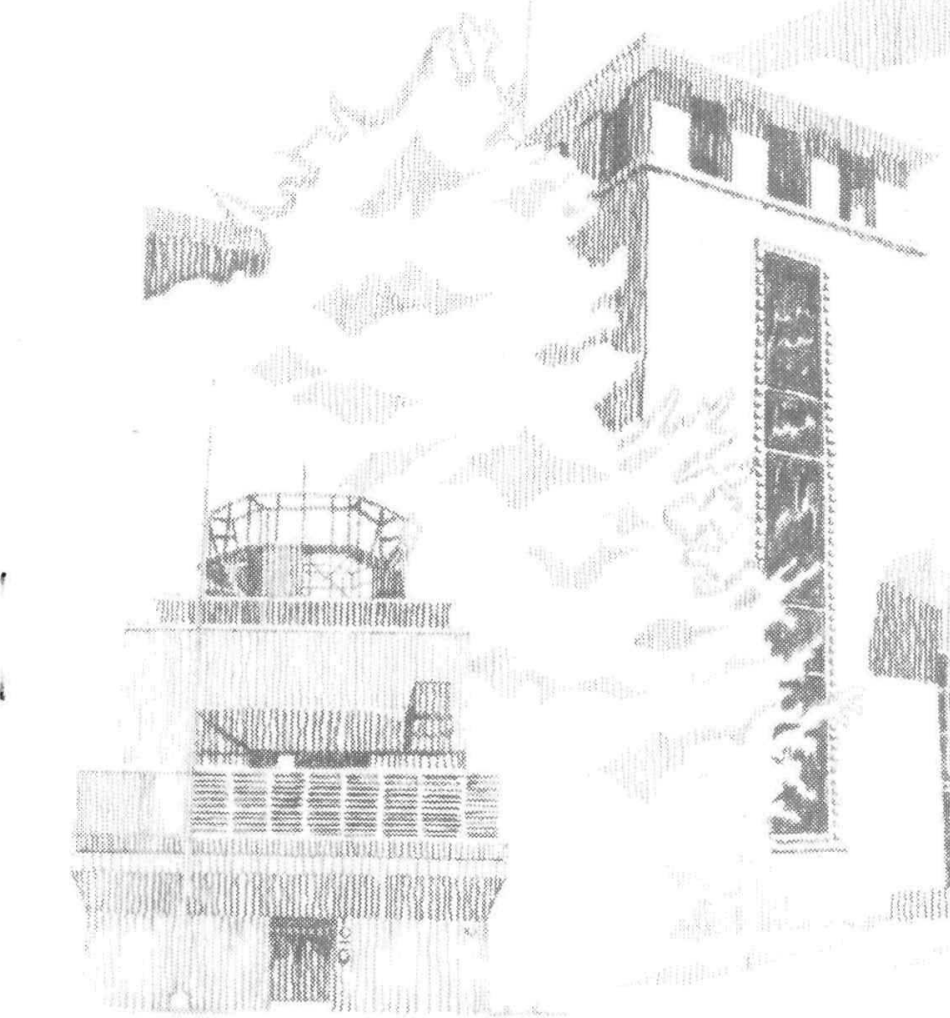
Issued by Sandia National Laboratories, operated for the United States Department of Energy by Sandia Corporation.

NOTICE: This report was prepared as an account of work sponsored by an agency of the United States Government. Neither the United States Government nor any agency thereof, nor any of their employees, nor any of their contractors, subcontractors, or their employees, makes any warranty, express or implied, or assumes any legal liability or responsibility for the accuracy, completeness, or usefulness of any information, apparatus, product, or process disclosed, or represents that its use would not infringe privately owned rights. Reference herein to any specific commercial product, process, or service by trade name, trademark, manufacturer, or otherwise, does not necessarily constitute or imply its endorsement, recommendation, or favoring by the United States Government, any agency thereof or any of their contractors or subcontractors. The views and opinions expressed herein do not necessarily state or reflect those of the United States Government, any agency thereof or any of their contractors.

Printed in the United States of America. This report has been reproduced directly from the best available copy.

Available to DOE and DOE contractors from

Office of Scientific and Technical Information

PO Box 62

Oak Ridge, TN 37831

Prices available from (615) 576-8401, FTS 626-8401

Available to the public from

National Technical Information Service

US Department of Commerce

5285 Port Royal Rd

Springfield, VA 22161

NTIS price codes

Printed copy: A03

Microfiche copy: A01 


\section{DISCLAIMER}

This report was prepared as an account of work sponsored by an agency of the United States Government. Neither the United States Government nor any agency Thereof, nor any of their employees, makes any warranty, express or implied, or assumes any legal liability or responsibility for the accuracy, completeness, or usefulness of any information, apparatus, product, or process disclosed, or represents that its use would not infringe privately owned rights. Reference herein to any specific commercial product, process, or service by trade name, trademark, manufacturer, or otherwise does not necessarily constitute or imply its endorsement, recommendation, or favoring by the United States Government or any agency thereof. The views and opinions of authors expressed herein do not necessarily state or reflect those of the United States Government or any agency thereof. 


\section{DISCLAIMER}

Portions of this document may be illegible in electronic image products. Images are produced from the best available original document. 


\title{
Lightning Threat Warning System at the Tonopah Test Range
}

\author{
Roger Smith \\ Telemetry and Communications Division \\ Sandia National Laboratories \\ Tonopah Test Range \\ Albuquerque, NM 87185
}

\begin{abstract}
This report documents the lightning threat warning system at the Tonopah Test Range and the technology it uses. The report outlines each of the system's individual components and the information each contributes.
\end{abstract}




\section{-}




\section{Contents}

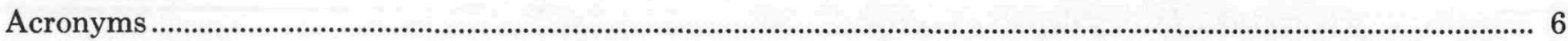

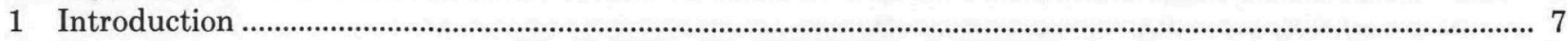

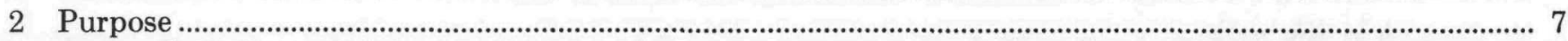

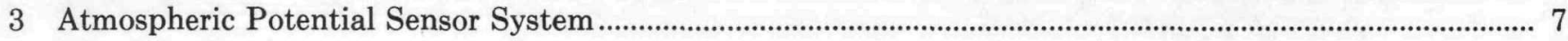

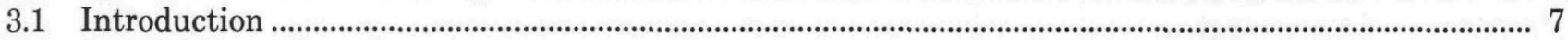

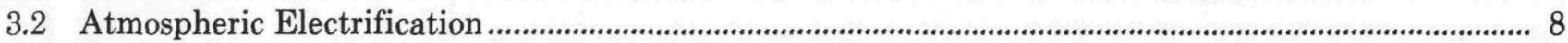

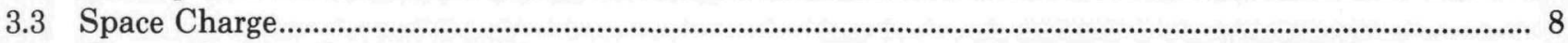

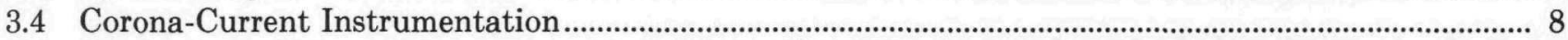

3.5 Atmospheric Potential Sensors vs. the Electric Field Mill ................................................................. 9

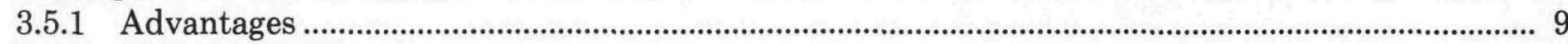

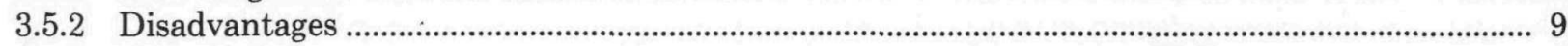

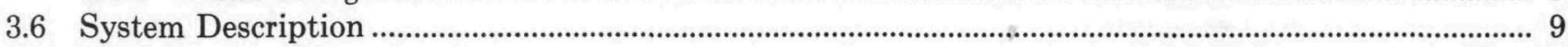

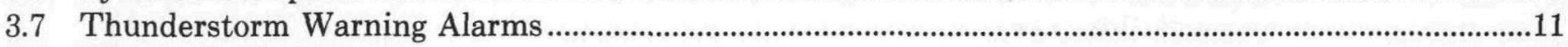

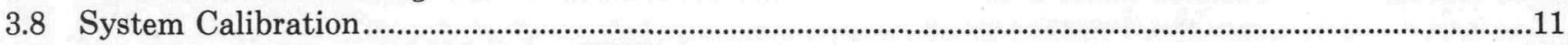

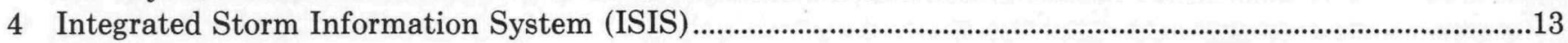

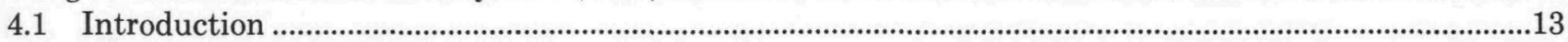

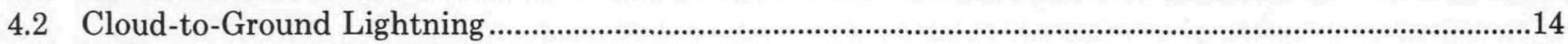

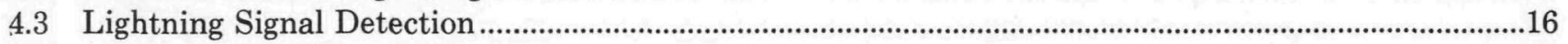

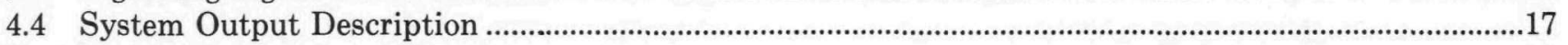

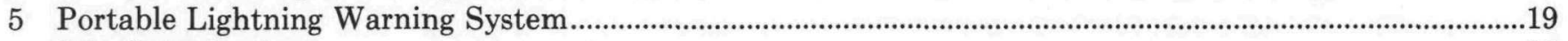

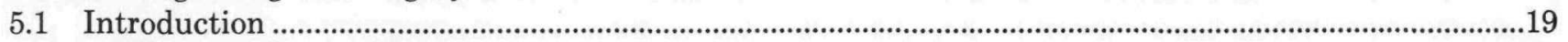

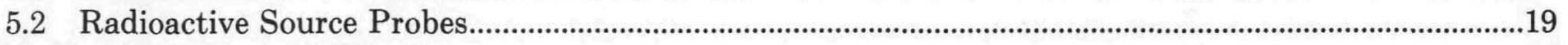

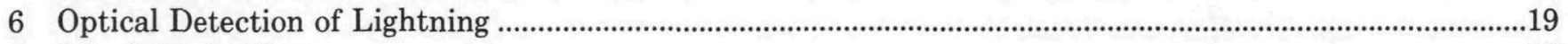

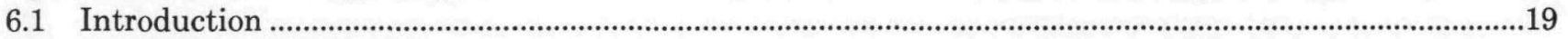

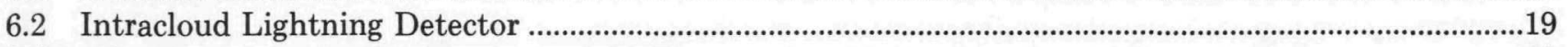

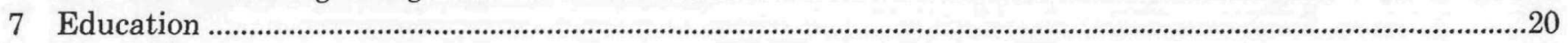

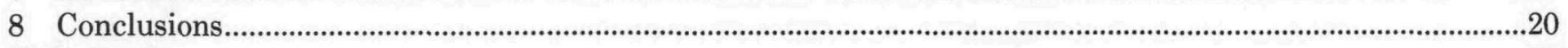

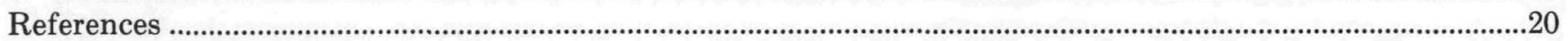

\section{Figures}

1 The Tonopah Test Range Lightning Threat Warning System …............................................................ 7

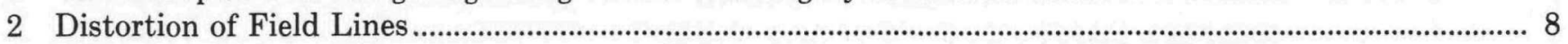

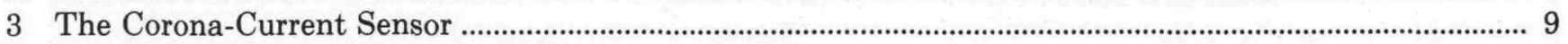

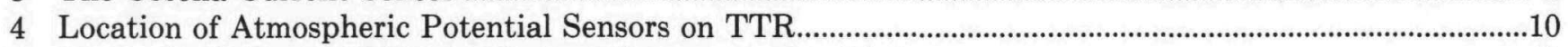

5 Atmospheric Potential Sensor System Communication Link ..........................................................................10

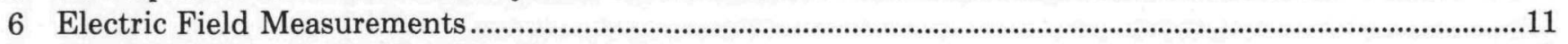

7 The HV-1 Electric Field Calibration System..................................................................................................12

8 The Calibration Display of the Atmospheric Potential Sensor System...........................................................12

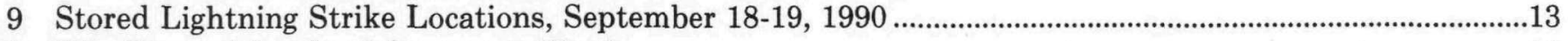

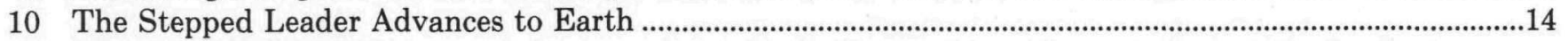

11 Grounded Objects Discharge a Streamer of Positively Charged Ions Upward Toward the Stepped

Leader as the Leader Approaches the Ground ......................................................................................................15

12 The Luminous Return Stroke Carries the Ground Potential Up to the Cloud...........................................15

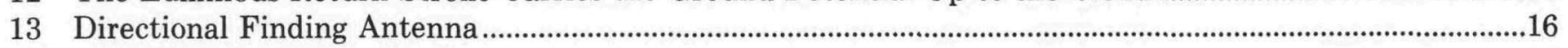

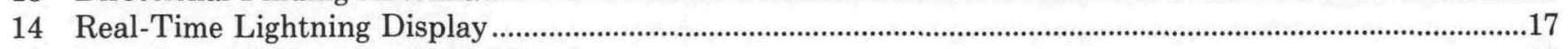

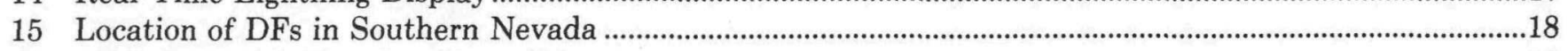

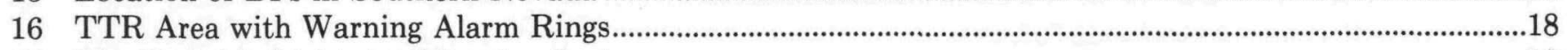

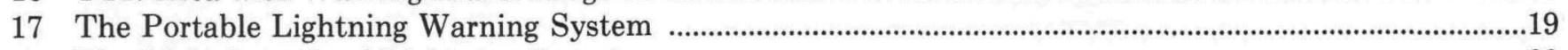

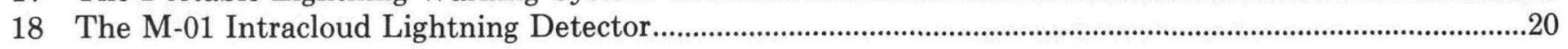




\section{Acronyms}

$\begin{array}{ll}\text { ALDS } & \text { automatic lightning detection system } \\ \text { APSS } & \text { atmospheric potential sensor system } \\ \text { C-C } & \text { cloud-to-cloud } \\ \text { C-G } & \text { cloud-to-ground } \\ \text { DF } & \text { direction finder } \\ \text { EM } & \text { electromagnetic } \\ \text { IC } & \text { intracloud } \\ \text { ISIS } & \text { integrated storm information system } \\ \text { LTWS } & \text { lightning threat warning system } \\ \text { NTS } & \text { Nevada Test Site } \\ \text { PA } & \text { position analyzer } \\ \text { SOP } & \text { standard operating procedure } \\ \text { TTR } & \text { Tonopah Test Range }\end{array}$




\section{Lightning Threat Warning System at the Tonopah Test Range}

\section{Introduction}

The Tonopah Test Range (TTR) lightning threat warning system (LTWS) comprises individual components, each contributing its own unique information. This information can be interpreted individually or combined into a comprehensive analysis of a developing lightning threat.

The LTWS consists of:

- an atmospheric potential sensor system (APSS) with associated warning and cautionary alarms

- an integrated storm information system (ISIS)

- a portable Sweeney lightning warning system (SLWS)

- intracloud lightning detectors

- an education program.

The output display monitors for the APSS and the ISIS are located on the fourth floor of the TTR Operations Center. (See Figure 1.)

\section{Purpose}

The purpose of the lightning threat warning system (LTWS) is to provide timely and credible information on developing lightning threats to "responsible individuals." Based on this information, these individuals will decide whether work will continue, stop, or resume. The ES\&H Standard Operating Procedures (SOP 701149002) govern the operation of the LTWS at TTR.

\section{Atmospheric Potential Sensor System}

\subsection{Introduction}

Atmospheric electrification increases in the presence of frontal and convective storm conditions before lightning occurs. Monitoring this increase can provide a warning period before the occurrence of a lightning threat. The common instrument to measure the "electric field" is the electric field mill; the mill measures the field at ground level. A new instrument, the atmospheric potential sensor, also measures atmospheric electrification, but uses corona-current technology to measure the electric field. This is the first commercially available, electric-field measuring instrument that utilizes corona discharge, is able to work in fair-weather fields, and is relatively insensitive to wind.

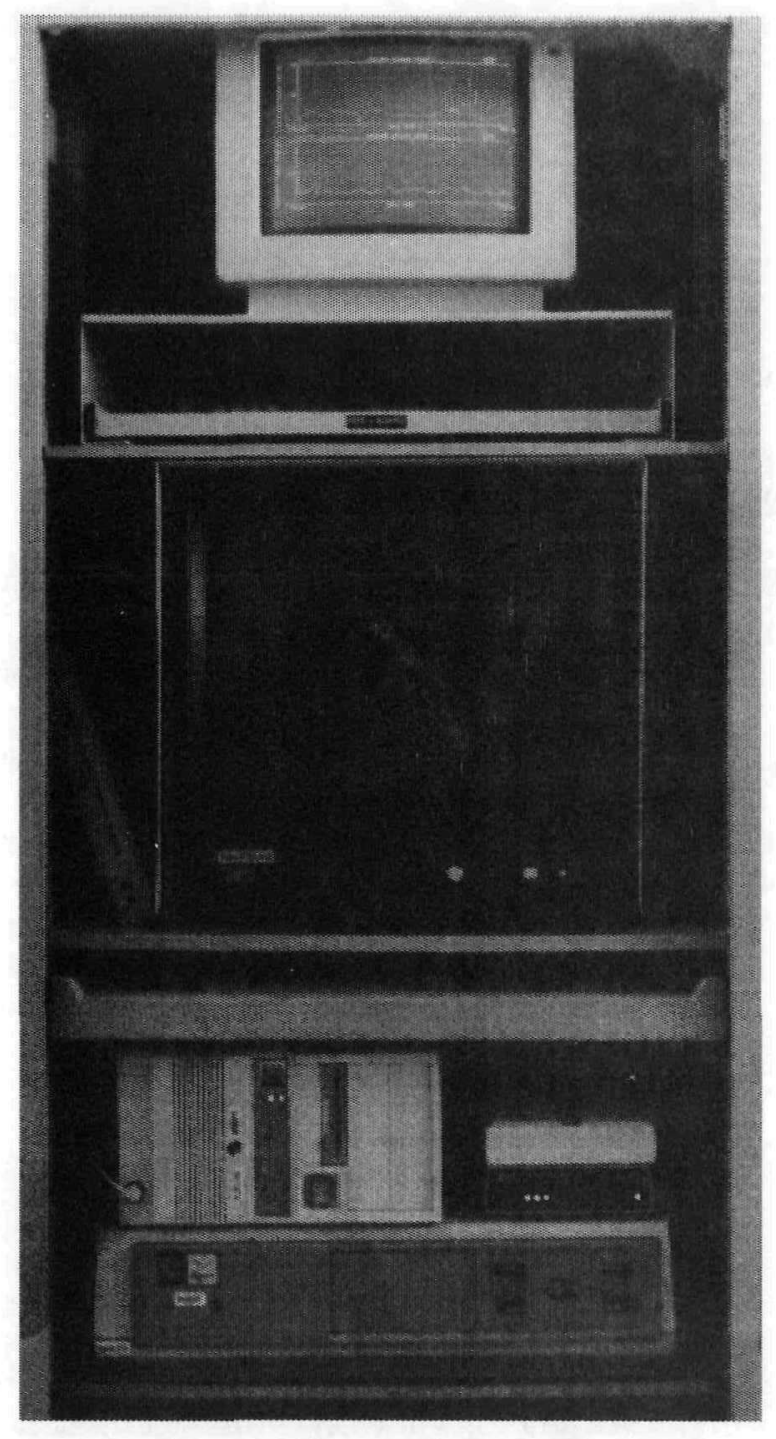

Figure 1. The Tonopah Test Range Lightning Threat Warning System 


\subsection{Atmospheric Electrification}

Atmospheric electrification can be expressed as an electrical circuit. The elements of this global circuit are the earth's resistance, atmospheric resistance, and the atmospheric potential. The generator for this circuit comprises the approximately 2000 thunderstorms in progress at any given time around the earth. These elements interact to produce an average fair weather electric field of approximately $100 \mathrm{~V} / \mathrm{m}$.

When charged storms move into an area or develop overhead, the local electric field will change from its fair-weather value. A significant increase in the magnitude of the field allows cloud-to-ground (C-G) lightning to occur. The monitoring of this electric field with its deviations from the fair-weather value can provide a warning period before lightning becomes a threat.

\subsection{Space Charge}

There are several problems in trying to measure an electric field accurately. A phenomenon known as space charge exists as an unknown variable in this measurement. Sharp-pointed objects elevated above the ground will go into corona-point discharge when the magnitude of the electric field exceeds $\sim 2000$ $\mathrm{V} / \mathrm{m}$. This produces a monopolar ion cloud, a space charge, that has polarity opposite that of the charge in the base of the corona-producing cloud. This effect will reduce the field intensity being measured by a surface-mounted electric field mill. The breaking of bubbles from waves and surf can also produce a space charge. ${ }^{1}$ Wind can blow the space charge over adjacent land areas in which electric field measurements are being taken. These ions have the same polarity as the base of the charged cloud, and enhance the field intensity. ${ }^{2}$ Space charge screening from these various sources, including the sensor itself, will affect the local electric field in an unknown and time-varying manner which will interfere with the reliable detection of the critical cloud-to-ground electric field intensity.

An electric field enhancement problem affects the calibration of the electric field mill. When a charged body is located above a large, flat, conductive ground plane, the electric field lines are normal to the plane, with uniformly spaced equipotential planes parallel to the ground plane. ${ }^{3}$ A local discontinuity in the ground plane, such as an upward protrusion from a field mill (Figure 2), will thereby influence the indicated field value. ${ }^{2}$ To compensate for this effect, a calibration correction factor, sometimes referred to as a "form factor", is derived by exposing the device to a known field and taking the ratio of the known field intensity to that indicated by the instrument. However, at field levels above the onset threshold of corona from its own housing, the additional problem of self-screening occurs. Since this phenomenon is both non-linear and time varying, a simple correction is not available.

In principle, a solution to the general, spacecharge layer problem is to make electric field mill measurements above the space charge. Elevating the field mill 15 meters or more above the ground places it higher than a significant portion of the space charge. This is not a practical solution as the field mill becomes charged through induction. The charge on the structure or on signal wires that run up a pole distorts the local field and leads to the same problems of interpreting the indicated results as was seen in space charge screening.

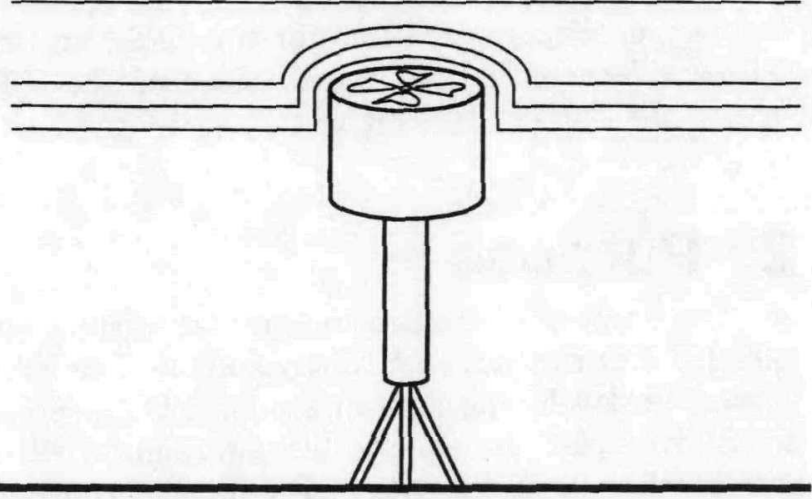

Figure 2. Distortion of Field Lines

\subsection{Corona-Current Instrumentation}

The corona-current sensor (Figure 3) measures an electric field while avoiding the problems associated with a space charge. ${ }^{2}$ This instrument has no moving parts, and is mounted approximately 15 meters above the ground on a tower or pole. It uses a very sharp needle energized by $300 \mathrm{kV}$; the voltage is applied through a resistance/capacitance network. The voltage keeps the needle in corona and produces a constant ion cloud around the tip. The sensor measures the current caused by the potential difference between the needle and the surrounding atmosphere. Wind can cause the resistance of the ion cloud around 


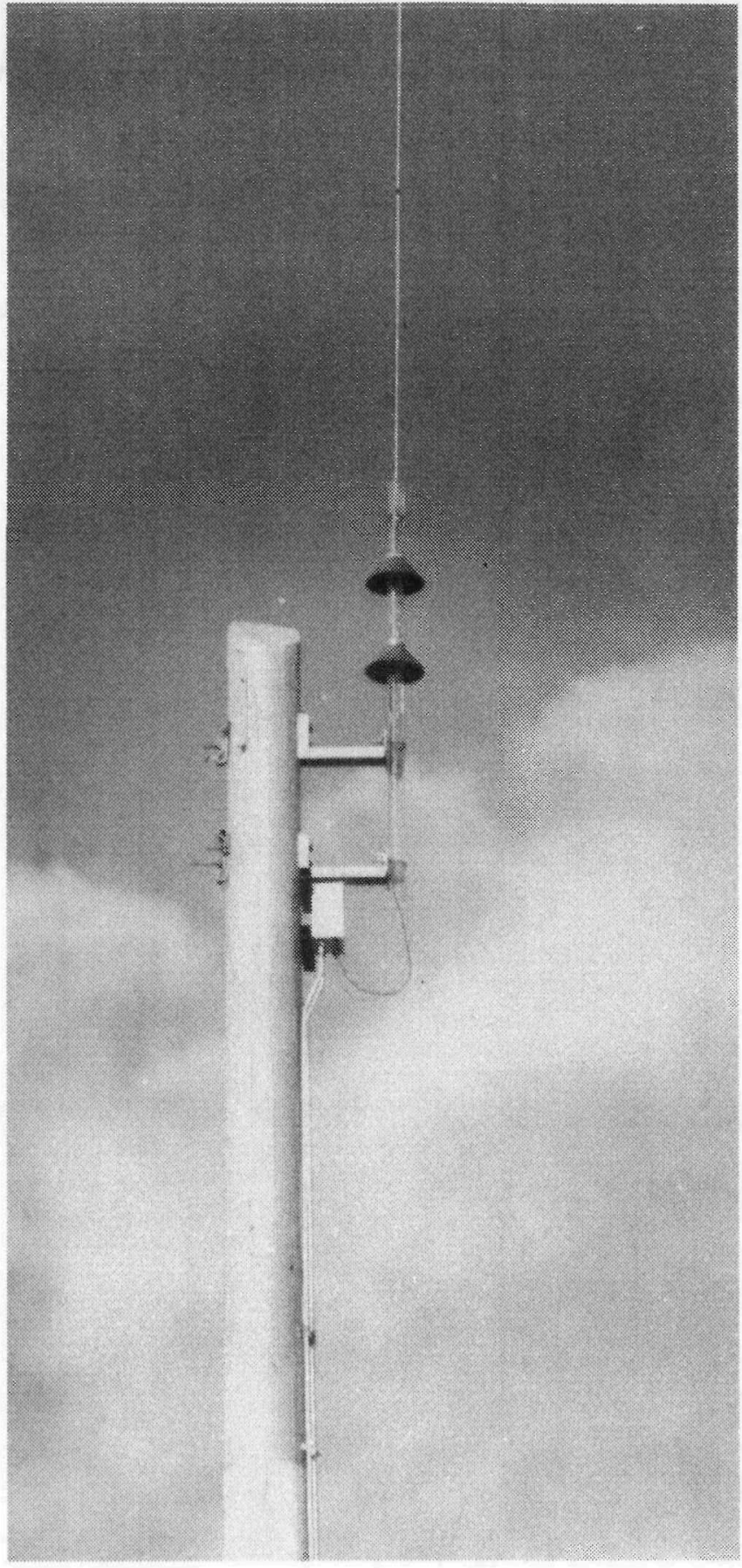

Figure 3. The Corona-Current Sensor

the needle to fluctuate. A large (50 G $\Omega$ ) resistance is used in the input circuit so that most of the I/R drop occurs across this known stable resistance instead of at the variable resistance of the ion cloud. This makes the instrument relatively insensitive to wind. The measured current is proportional to the atmospheric potential at the height of the needle. By dividing the measured potential by the height of the needle, the average field intensity from the ground to that height can be determined. A calibration procedure for the system normalizes the sensor output to determine the average field intensity. The final output of the APSS is an electric field measurement in $\mathrm{V} / \mathrm{m}$.

\subsection{Atmospheric Potential Sensors vs. the Electric Field Mill}

\subsubsection{Advantages}

The APSS are mechanically simple and require little maintenance. They are relatively unaffected by wind, rain, snow, sand, or insects. The corona needle is less sensitive to space charge since it is higher than most of the charged ions produced by the corona from the surrounding terrain. With less space charge interference, its form factor is proportionately less affected. The power requirements are small enough to allow installation at remote sites where only solar cells and/or batteries are available.

\subsubsection{Disadvantages}

Installation on a tower or pole may require climbing the pole or using a bucket truck. Servicing the needle could also present a problem. Since the sensor is on an elevated pole, it could be susceptible to lightning strikes. Also, at oceanside sites, there may be a problem maintaining a $50 \mathrm{G} \Omega$ resistance.

\subsection{System Description}

The APSS was developed by Airborne Research Associates. $^{2}$ Three model P-1 corona-current type sensors are used at TTR (see Figure 4). One sensor is located near the artillery gun firing facility in Area 9; the second is next to the TTR weather station; a third is located in Area 49. Each sensor output is fed into a modem for transmission to the system's computer via a dedicated telephone circuit. A modem distribution box is used in the data stream to enable the operator to bypass the communication link from an inoperative sensor (Figure 5). The computer is an IBM $\mathrm{PC} / \mathrm{AT}$ compatible with high resolution color graphics (VGA with $640 \times 480$ resolution). The software was written in Borland Turbo $\mathrm{C}$ by Airborne Research Associates. The program inputs the data through the computer's RS232 interface, stores it on a hard disk, and presents the data from each sensor in a real-time graphic display of $\mathrm{V} / \mathrm{m}$ as a function of time (Figure 6). The program has four alarm points that can be set. The computer will provide an output 
signal closure for cautionary alarms when electric field levels exceed $-500 \mathrm{~V} / \mathrm{m}$ or $+1000 \mathrm{~V} / \mathrm{m}$. The program also provides an output signal closure for warning alarms when levels exceed $-1000 \mathrm{~V} / \mathrm{m}$ or $+2000 \mathrm{~V} / \mathrm{m}$. The menu-driven program also enables the operator to change setup parameters, to silence alarms, and to test the alarms. With a printer installed, a screen dump can be performed. Stored data may also be displayed.

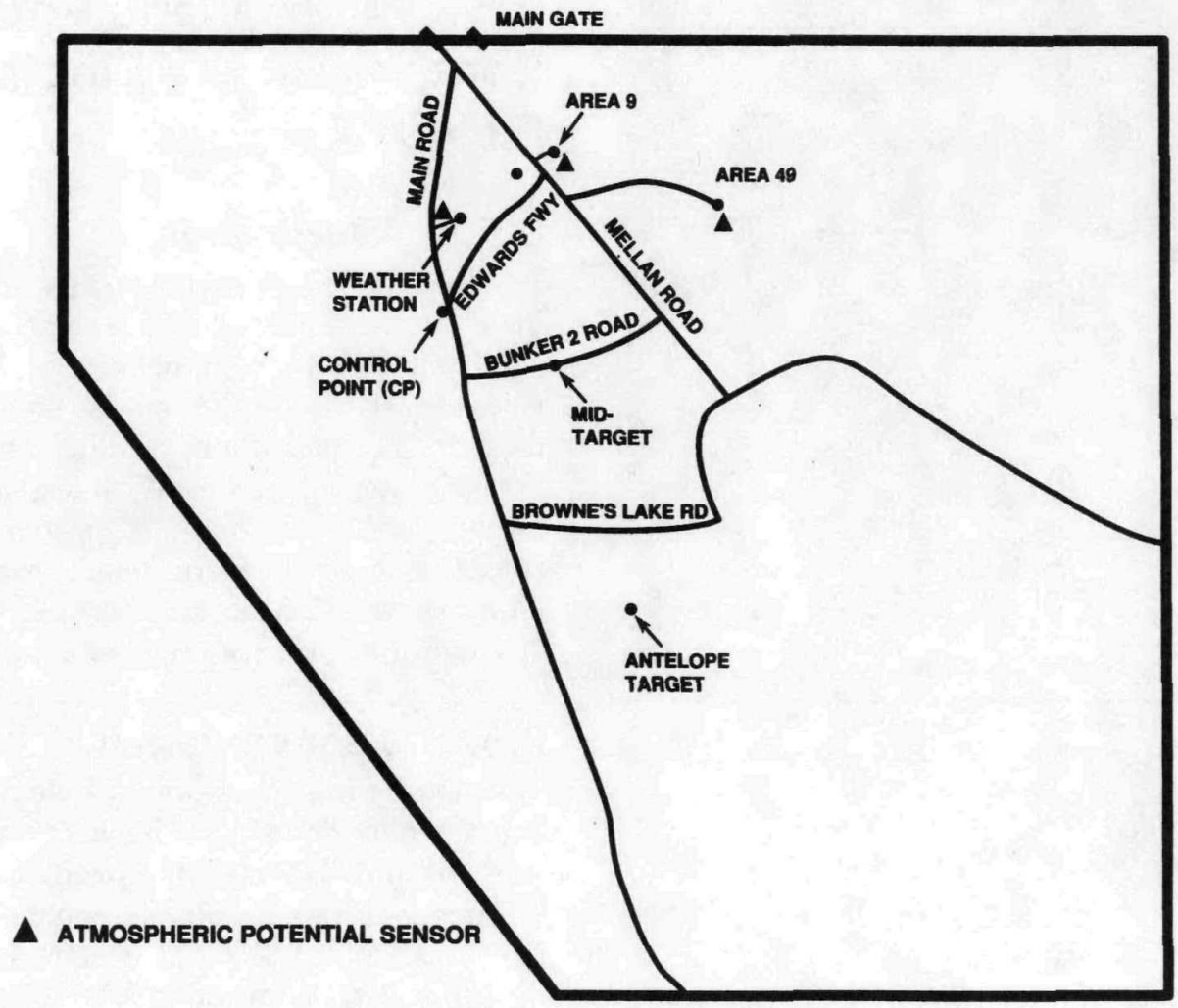

Figure 4. Location of Atmospheric Potential Sensors on TTR

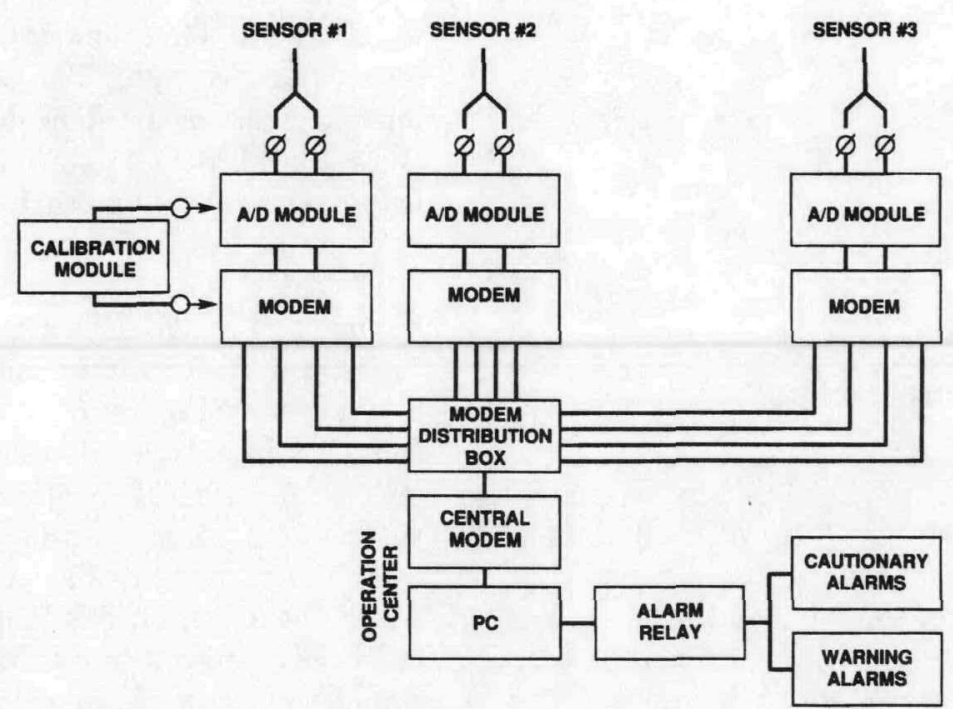

Figure 5. Atmospheric Potential Sensor System Communication Link 


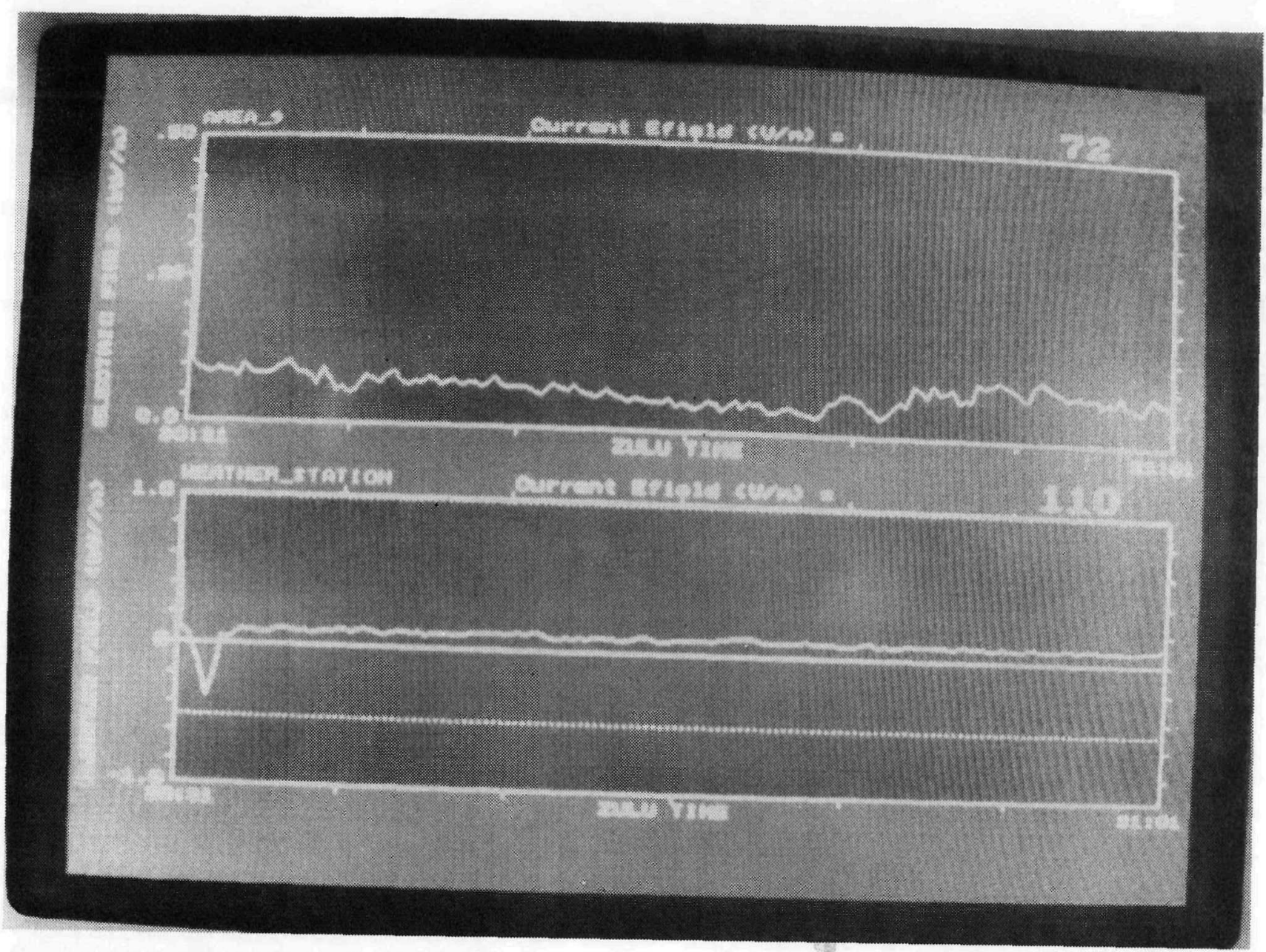

Figure 6. Electric Field Measurements

\subsection{Thunderstorm Warning Alarms}

When the electric field as detected by the sensor exceeds alarm levels, visual and audio alarms activate in Areas 9 and 49. When cautionary levels of -500 $\mathrm{V} / \mathrm{m}$ and $+1000 \mathrm{~V} / \mathrm{m}$ are exceeded, yellow lights flash in Building 9A and on the Launcher 2 Tower in Area 9 and on the Blockhouse Tower in Area 49. When warning levels of $-1000 \mathrm{~V} / \mathrm{m}$ and $+2000 \mathrm{~V} / \mathrm{m}$ are exceeded, the computer alarm sounds, along with horns, on Area 9's Launcher 2 Tower, in the explosive storage area, and in the explosive assembly buildings. Red lights will flash in Building 9A, on the rocket, gun, and visitor bunkers, on the Launcher 2 Tower, on the Gun Bunker Tower, and in the explosive storage area. In Area 49, a red light will flash on the Blockhouse Tower and a horn will sound. A lightning warning condition will continue for 30 minutes after the electric field level drops below $-1000 \mathrm{~V} / \mathrm{m}$ or $+2000 \mathrm{~V} / \mathrm{m}$. Determining what constitutes the alarms is mandated by ES\&H SOP SP471969. These levels were determined by Sandia National Laboratories (Department of Environment, Safety, and Health) and TTR Range Safety personnel.

\subsection{System Calibration}

Calibration is accomplished by an Airborne Research Associates model HV-1 electric field calibration system (Figure 7). The calibration unit is placed $\sim 100 \mathrm{~m}$ from the desired sensor and connected to that sensor's modem with a computeraddressing module. At the computer terminal, the calibration program is selected and the setup parameters entered. The slope and intercept information provided is used for the gain and offset for that sensor (Figure 8). 


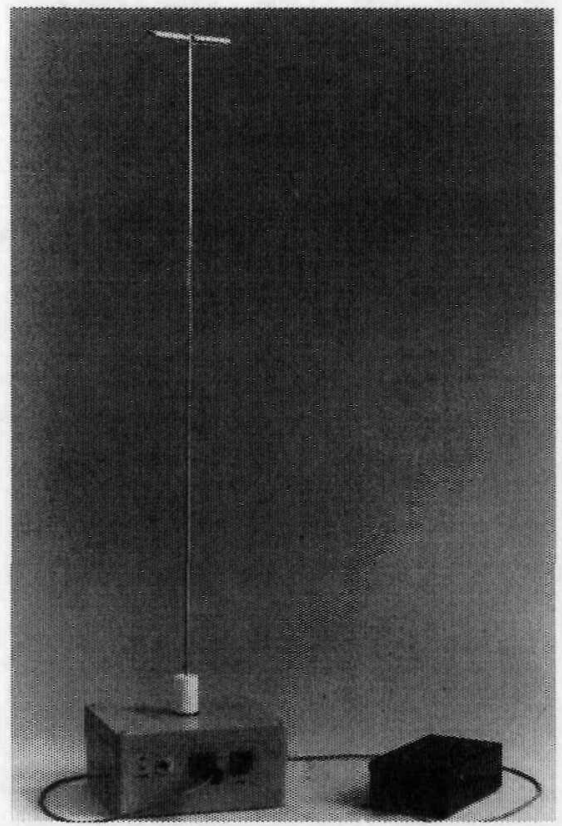

Figure 7. The HV-1 Electric Field Calibration System

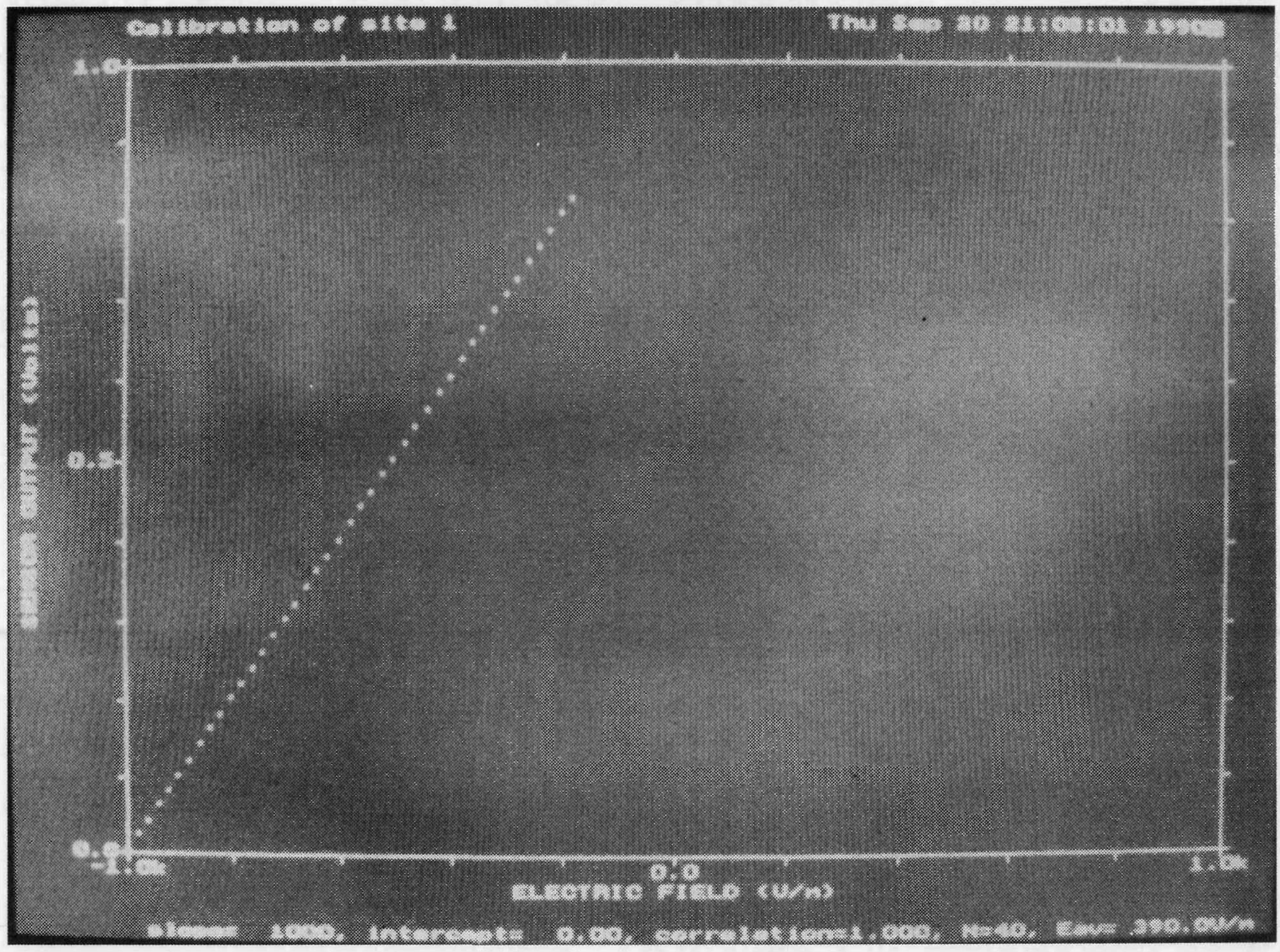

Figure 8. The Calibration Display of the Atmospheric Potential Sensor System 


\section{Integrated Storm Information System (ISIS)}

\subsection{Introduction}

The ISIS serves as a graphic display device in the Nevada Test Site (NTS) automatic lightning detection system (ALDS). The ISIS is an acquisition and display system with real-time ability to locate, identify, and track lightning-producing storm systems. It collects, processes, and displays lightning data automatically with minimum operator attention. The system has seven direction finder (DF) antennas to detect the electromagnetic (EM) impulses radiated by $\mathrm{C}-\mathrm{G}$ lightning. A position analyzer (PA) processes the data from the DFs and transmits the latitude, longitude, and polarity characteristics of the lightning strike covered by the ISIS. The ISIS converts this data to a map presentation and displays it on a high-resolution color video monitor (Figure 9). The spatial accuracy of the ISIS is a function of a variety of factors. These factors are the number of sensors, the distances between them, and local site errors peculiar to geological and geometric features that distort antenna patterns. The average error in flash location of the NTS ISIS as determined by the National Weather Service Nuclear Support Office is $1.3 \mathrm{~km} .{ }^{4}$ The lightning data are also stored and can be recalled at a later date. The ISIS is manufactured by Lightning Location and Protection, Inc., Tucson, Az.

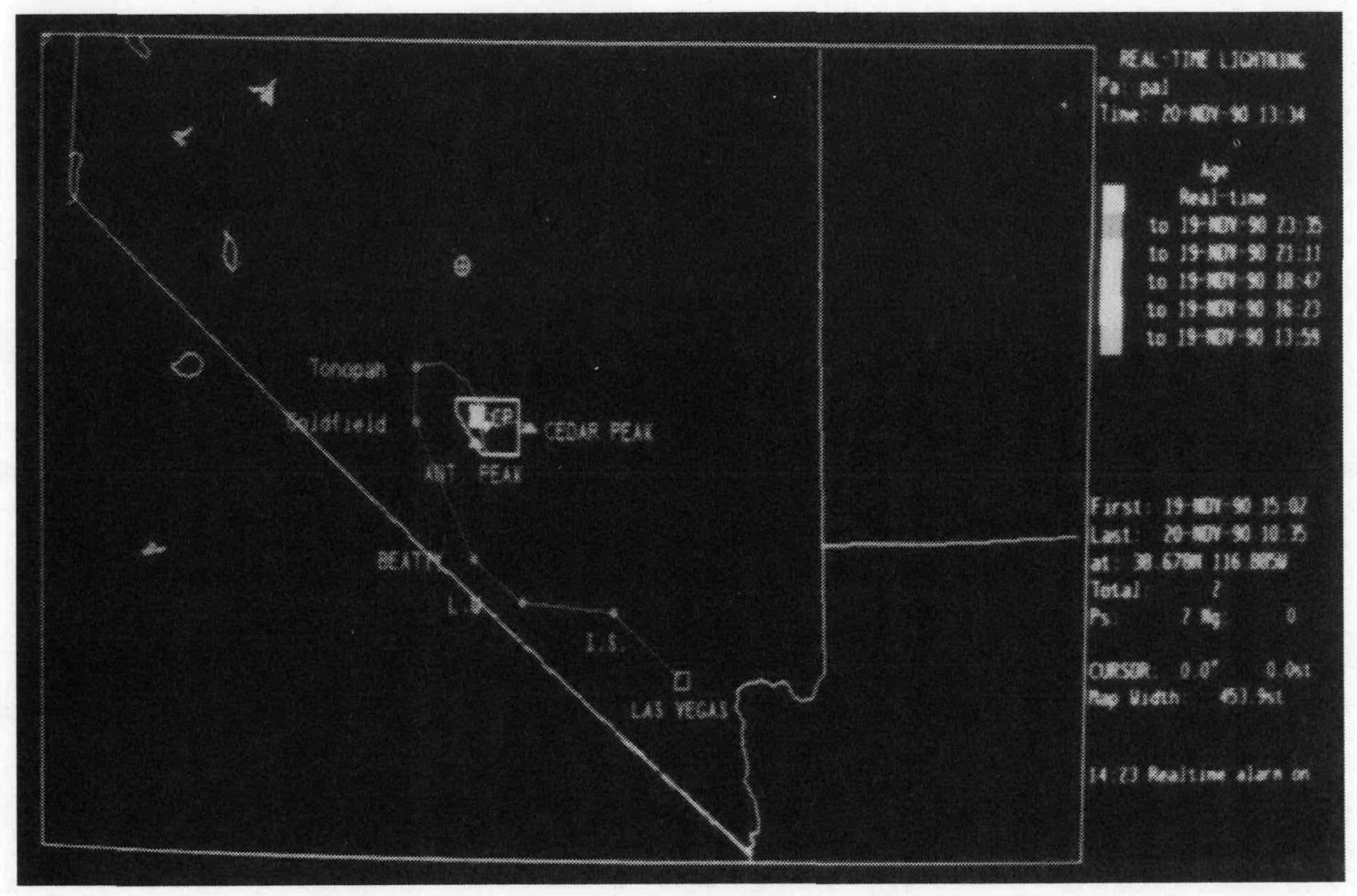

Figure 9. Stored Lightning Strike Locations, September 18-19, 1990 


\subsection{Cloud-to-Ground Lightning}

Lightning is a natural, high-current electrical discharge occurring in the atmosphere. C-G lightning occurs when electrical charges within a cloud increase enough to cause the electric field between the cloud and the earth to exceed the surrounding air's dielectric strength. When negative charges in the base of a cloud are large enough to produce a strong local electric field, a negatively charged ionized channel known as a stepped leader is produced which moves toward the earth (Figure 10). Grounded objects discharge a streamer of positively charged ions (emanating from the space charge provided by the corona point discharge) upward toward the stepped leader as the leader approaches the ground. (See Figure 11.) When the downward-going stepped leader comes in contact with one or more of the upward-going streamers, a path is created for the cloud's negative charges to be returned to the earth. A current surge then follows, with a typical peak amplitude at ground level of 20 to $30 \mathrm{kA} .^{5}$ This current pulse, known as a return stroke, has a polarity consistent with the effective lowering of electrons from the cloud to the earth. This very luminous return stroke carries the ground potential up this channel to neutralize the charge difference (Figure 12). Several return strokes may be produced, propagating up the path at 35 to $300 \mathrm{~m} / \mu$ s and causing thunder-producing overpressures. ${ }^{3}$ These return discharges are known as a "stroke," and the total discharge event is called a "flash." The magnetic field radiated by the return stroke current is received by multiple ISIS DFs and is processed to locate the flash.
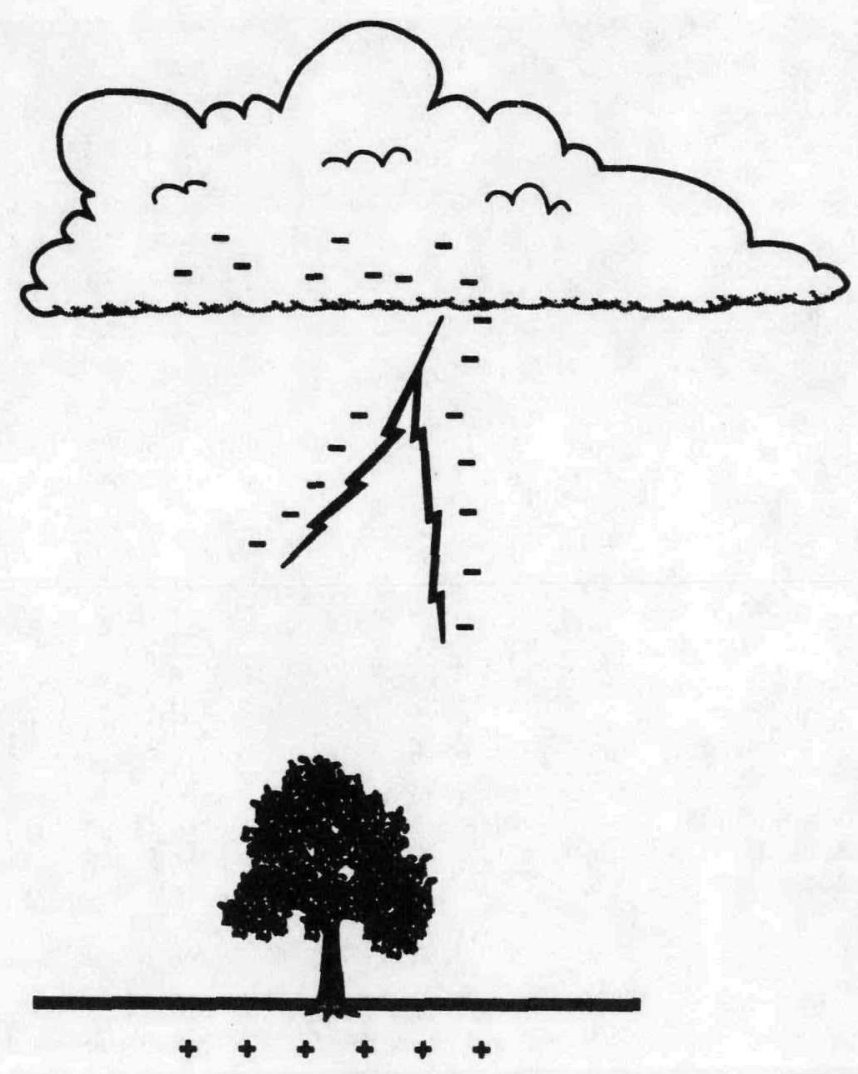

Figure 10. The Stepped Leader Advances to Earth 


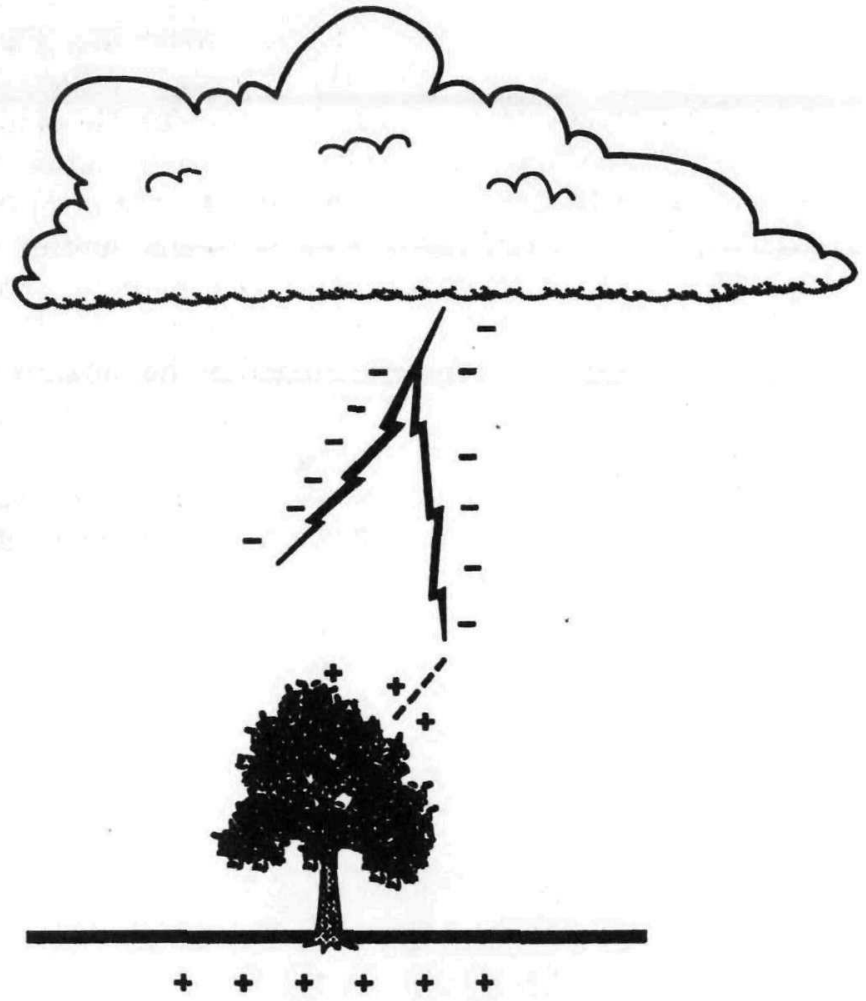

Figure 11. Grounded Objects Discharge a Streamer of Positively Charged Ions Upward Toward the Stepped Leader as the Leader Approaches the Ground

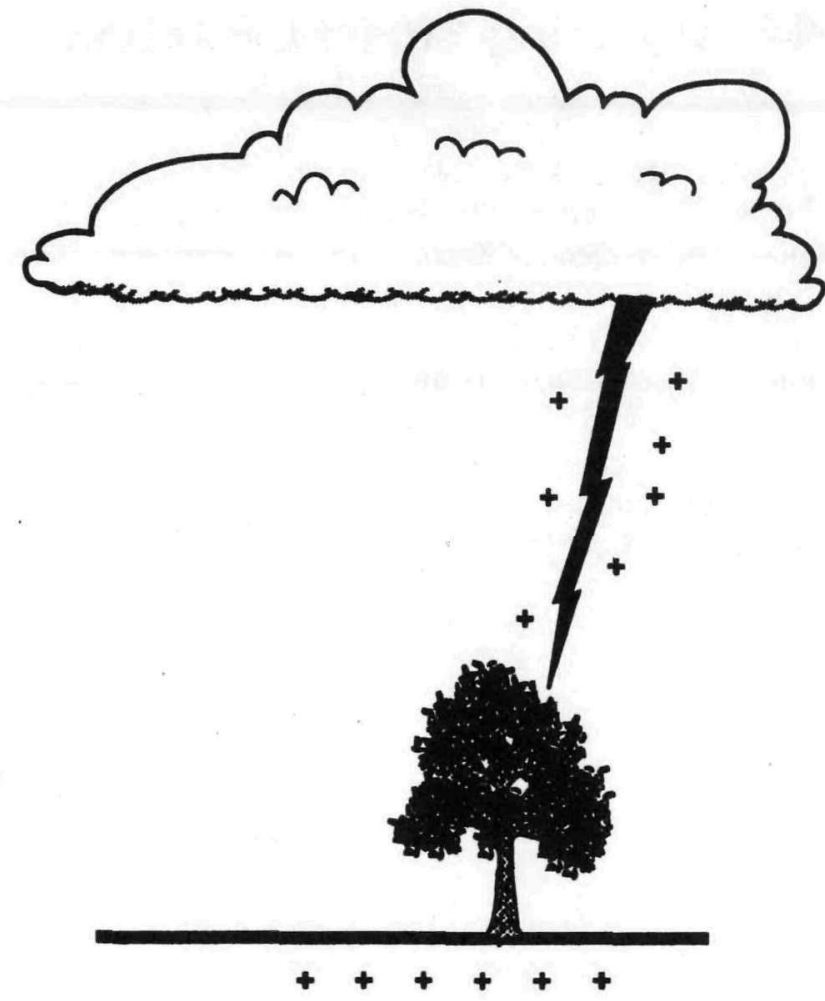

Figure 12. The Luminous Return Stroke Carries the Ground Potential up to the Cloud 


\subsection{Lightning Signal Detection}

Lightning return strokes radiate power in the range of 20,000 MW. The EM impulses created have a characteristic signature that can be detected for thousands of miles. The ISIS is designed to register only cloud-to-ground flashes by searching for certain characteristic features on the field fronts radiated by such flashes. The DF employs a pair of vertically polarized, crossed-loop antennas (Figure 13) which are precisely aligned with true north. When the lightning discharge impulses are received, the DF electronics measure their direction, polarity, and signal amplitudes. The DF then transmits a message with this information to the PA for processing. The PA timetags and processes the message. When it receives messages from two or more DFs for the same lightning strike, the PA calculates the coordinates of the strike by triangulation. The PA then transmits the latitude, longitude, and polarity of the lightning strike to the ISIS terminal. The ISIS displays that information on a user-defined map (Figure 14). The map region and scale can be changed by the operator. Alarm rings can be placed on the map to alert the operator of distant C-G lightning-producing storms. Unfortunately, the system will not provide a lightning threat warning from a charged storm that has not yet produced C-G lightning.

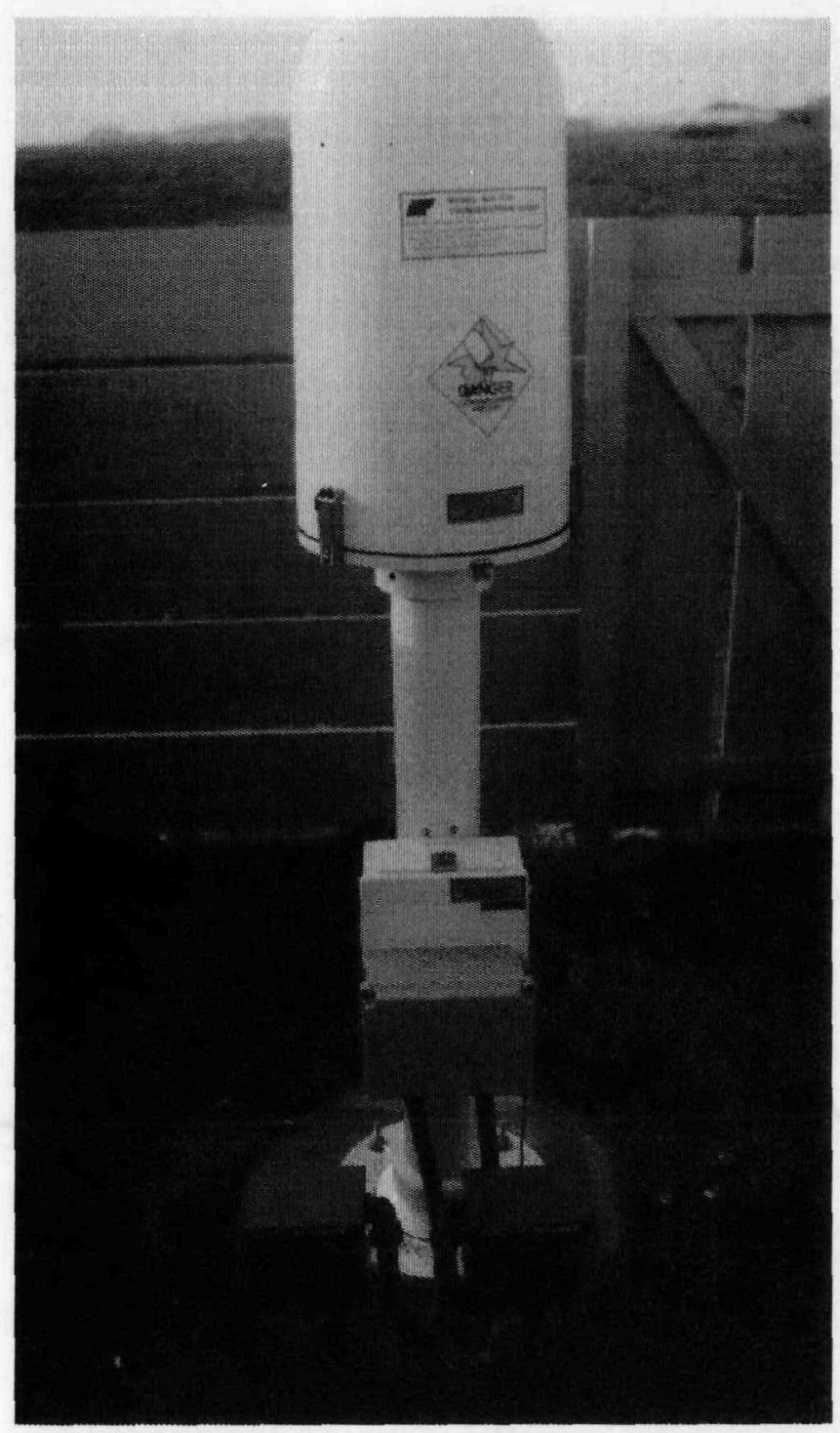

Figure 13. Directional Finding Antenna 


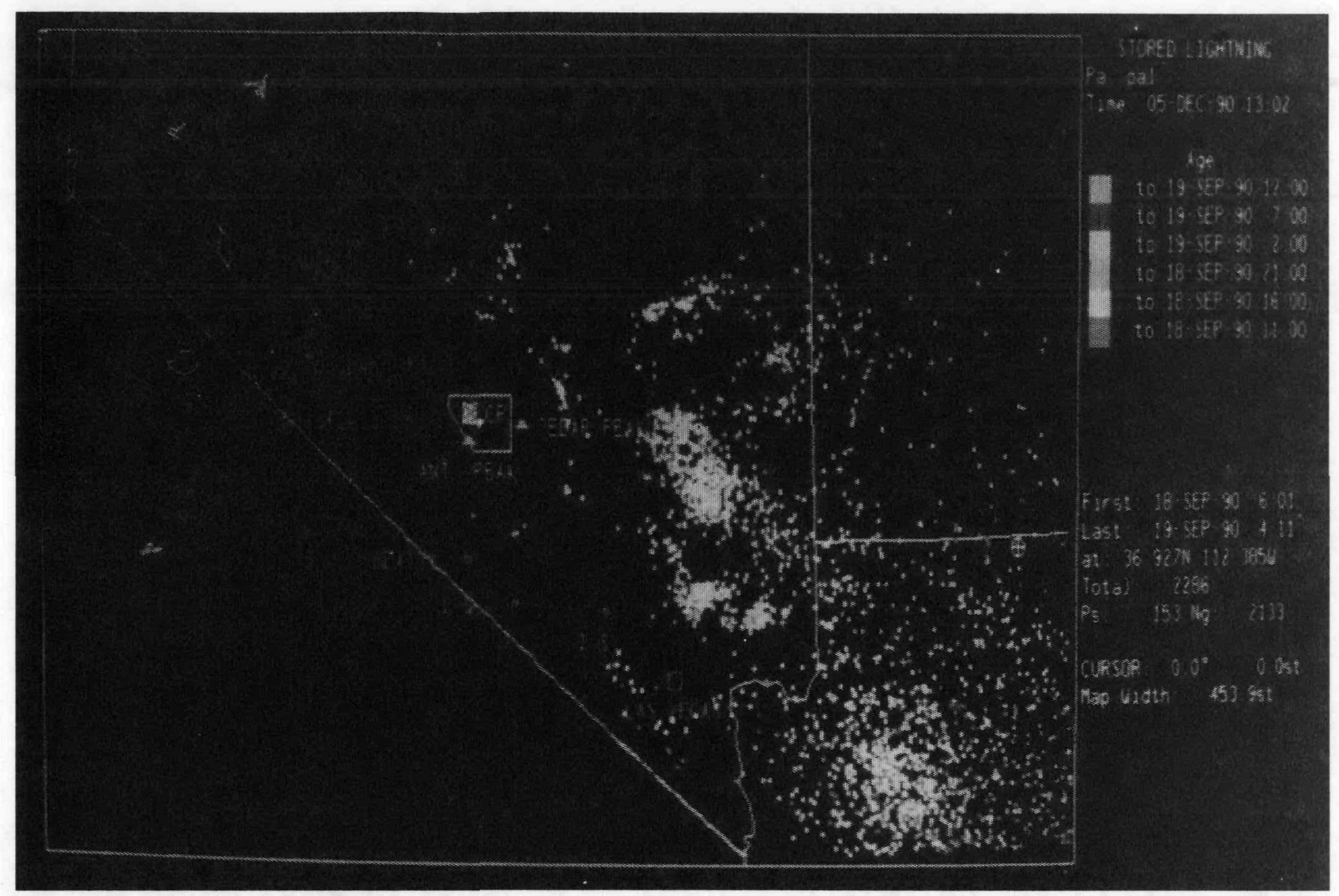

Figure 14. Real-Time Lightning Display

\subsection{System Output Description}

The ISIS is able to display lightning strikes detected by NTS ALDS. The ALDS, administered by the Weather Service Nuclear Support Office, has seven DFs located throughout southern Nevada (Figure 15). The ALDS also employs a computergenerated automated lightning alert system that ver- ifies the system's operational status and transmits the appropriate lightning threat alarms. The ISIS's regional maps display prominent land features, political boundaries, state highways, the TTR boundaries, and roads within the TTR boundaries. Alarm rings are set to alert the operator of lightning strikes within a 25 mile $(40 \mathrm{~km})$ radius of the TTR control point (Figure 16). 


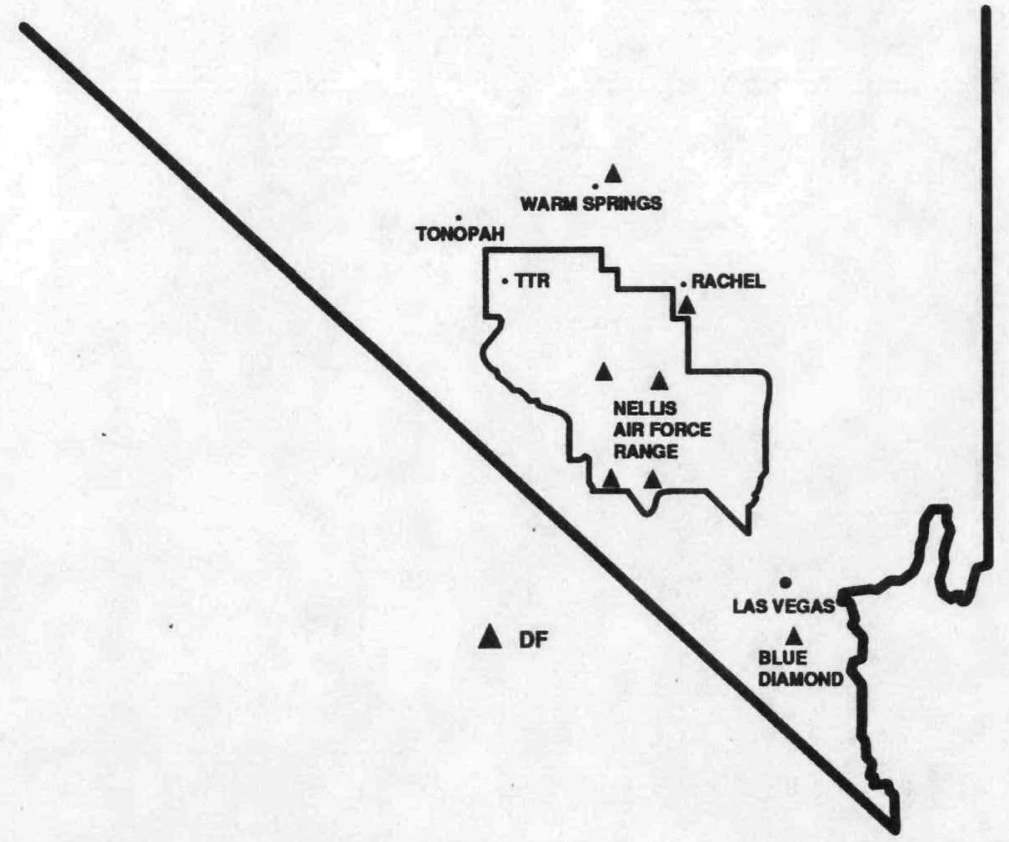

Figure 15. Location of DFs in Southern Nevada

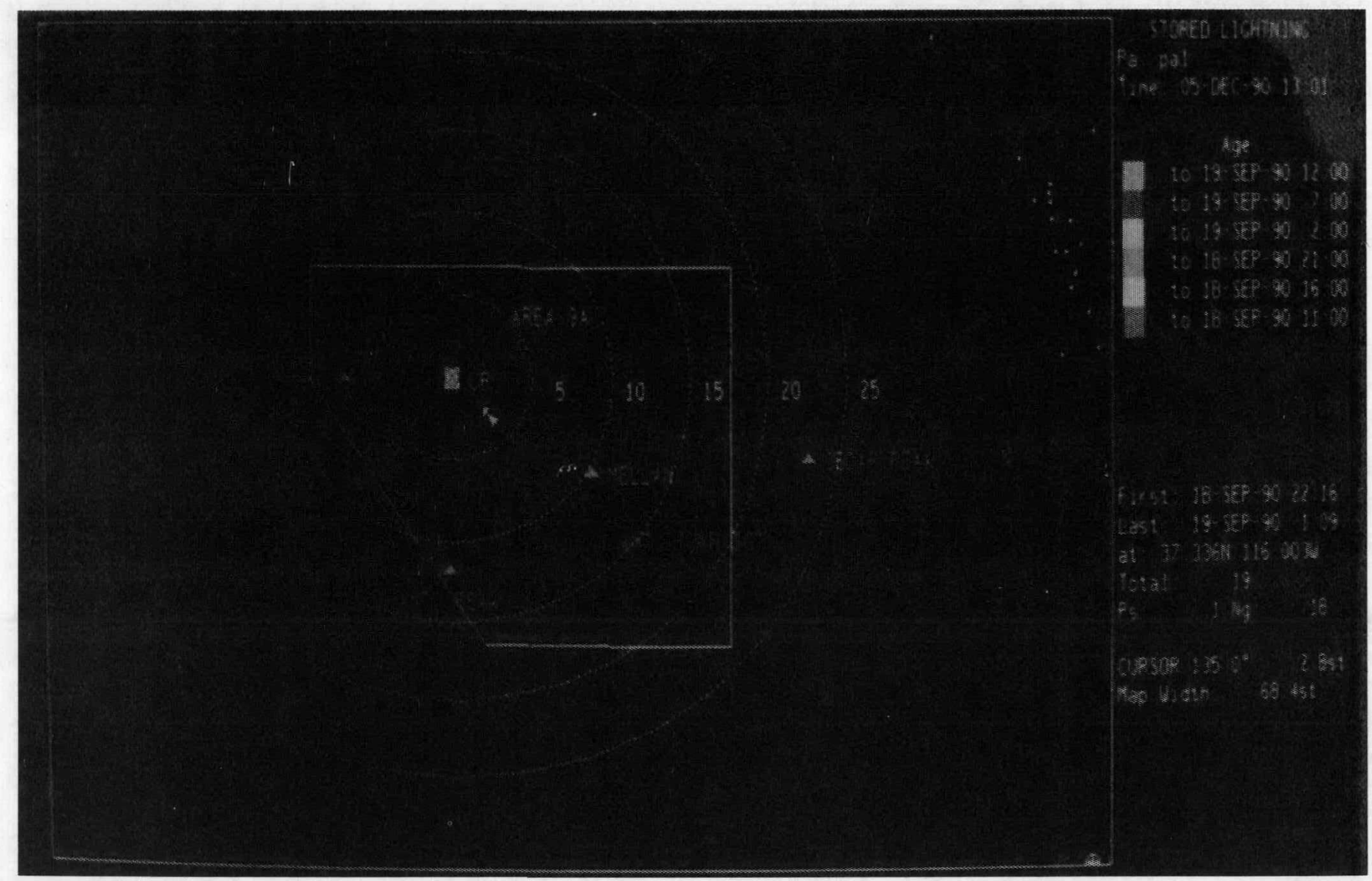

Figure 16. TTR Area with Warning Alarm Rings 


\section{Portable Lightning Warning System}

\subsection{Introduction}

The portable lightning warning system (Figure 17 ) is used as a lightning threat warning device for operations involving explosives conducted outside of Area 9. The system uses a radioactive source probe to measure atmospheric electric fields. Exceeding the alarm threshold of $\pm 2000 \mathrm{~V} / \mathrm{m}$ activates a visual and audio alarm. The portable warning system is Model OM-1196A, manufactured by B. K. Sweeney Mfg. Co.

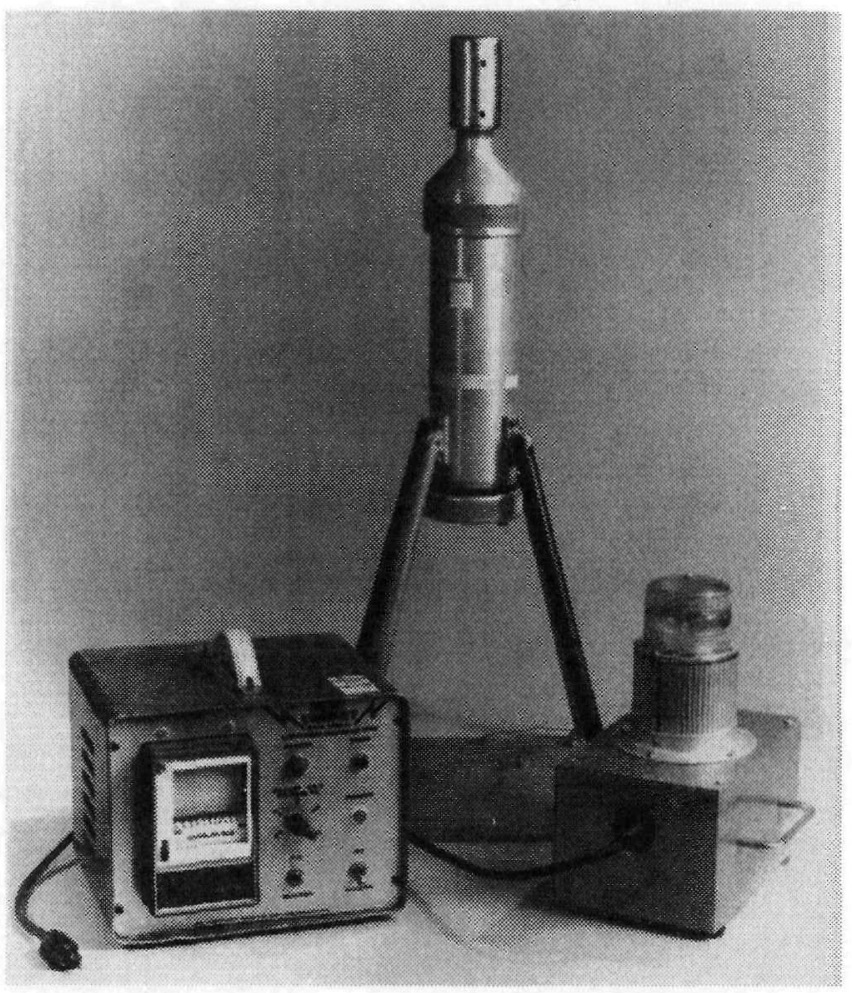

Figure 17. The Portable Lightning Warning System

\subsection{Radioactive Source Probes}

The probe used in the Sweeney system uses tritium as its radioactive source. This source is an alpha-particle emitter, and is not considered to be hazardous. The 1 meter-high probe is brought to the atmospheric potential from the ionization of the source. The potential difference between the probe and the ground is measured by a high impedance voltmeter; thus, the local electric field is obtained. Problems associated with this probe are: 1) maintaining the required high-input resistance, and 2) its low current saturation threshold when measuring large electric fields. These problems result in a non-linear performance of the probe. Current saturation, degeneration of electric components over time, and environmental exposure are variables that affect the performance of the probe.

\section{Optical Detection of Lightning}

\subsection{Introduction}

Lightning may be in the form of C-G, or intracloud (IC) lightning. IC lightning can occur between clouds (C-C) or can be contained within a single cloud. IC discharges can occur between negative and positive charge centers within or between clouds. Studies suggest that IC discharges can be precursors to C-G activity. ${ }^{6}$ The studies suggest IC discharges develop during the up-draft phase of a developing thundercloud and that $\mathrm{C}-\mathrm{G}$ activity can lag the initial IC peak by 5 to 10 minutes. The ability to detect IC lightning could provide up to a 10-minute warning period prior to the possible onset of $\mathrm{C}-\mathrm{G}$ activity. It should be noted that IC lightning should not be relied upon as a precursor to C-G activity.

\subsection{Intracloud Lightning Detector}

The intracloud lightning detector (Figure 18) Model M-01, constructed by Airborne Research Associates, responds to the optical signature of lightning. The detector is sensitive to signals from scattered or reflected light from high cirrus or other nearby clouds. Field tests indicate that IC lightning can be detected at ranges of up to $150 \mathrm{~km}$ during the day. ${ }^{4}$ The detector may be hand-held or placed on a camera tripod for unattended lightning monitoring. An audio alarm will alert personnel of detected lightning. This instrument can be useful when used in conjunction with electric field measurements in determining potential lightning hazards at remote operations.

Lightning detection within 10 miles of an operation involving explosives will constitute a lightning warning. Distances to lightning strikes, in miles, may be estimated by counting the seconds between the flash and its corresponding thunder and dividing by 5 (divide by 3 for $\mathrm{km}$ ). Sound travels approximately $1 / 5$ of a mile per second. 


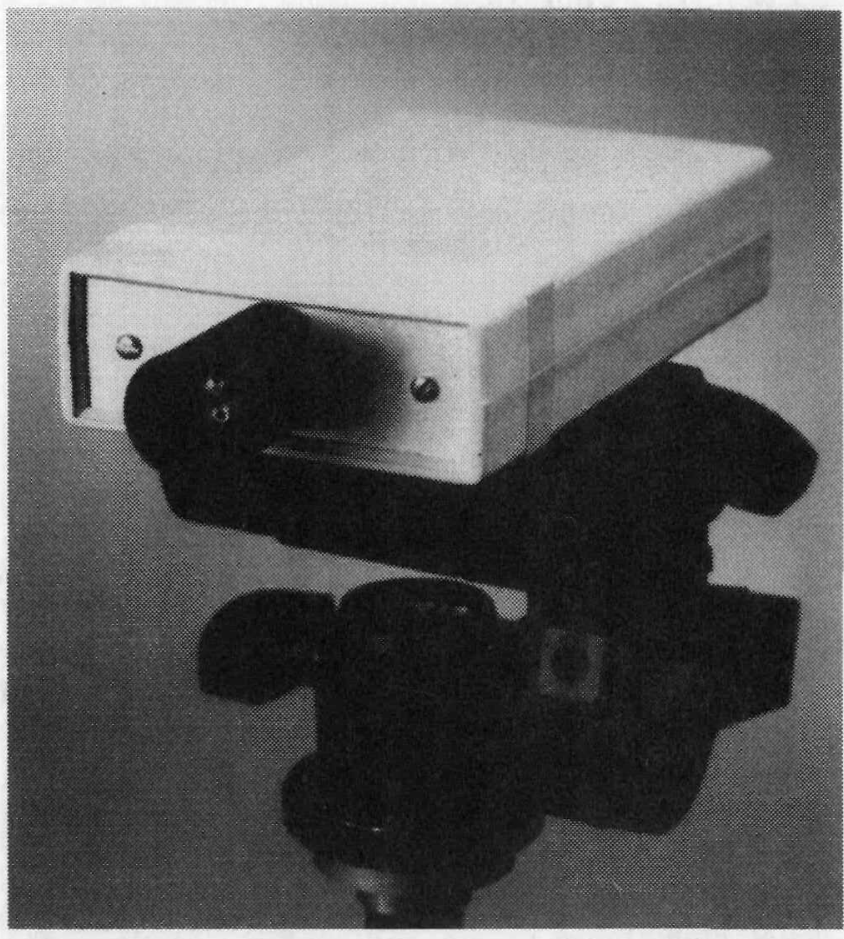

Figure 18. The M-01 Intracloud Lightning Detector

\section{Education}

The education component of the lightning threat warning system provides TTR personnel with an understanding of lightning, personal lightning protection, and the capabilities of the system. Thunderstorm development, atmospheric electrification, space charge, and intracloud and cloud-to-ground lightning are discussed in annual safety briefings. Personal lightning protection information includes avoiding open fields, towers, rooftops, and working on any elevated equipment during electrical storms. Personnel are also instructed to remain indoors or inside a closed motor vehicle during these storms.

TTR personnel are briefed on each component of the lightning threat warning system and on the information each component supplies. "Responsible" individuals are trained to assimilate system information and to make an appropriate evaluation of the lightning hazard. Lightning-threat warnings and appropriate personnel responses are also discussed. All TTR personnel are required to review ES\&H SOP SP471969: "The Operation of the Lightning Threat Warning System at the Tonopah Test Range." The training takes place during one of the semi-annual safety briefings.

\section{Conclusions}

A study is currently under way at the Tonopah Test Range to evaluate the overall performance of the atmospheric potential sensor system. This study will make a side-by-side comparison of the corona-current sensor and a field mill. The results will be released in a future report.

The purpose of this present report is to document the lightning threat warning system at TTR. We describe each of the system's components, the information each can contribute to the warning system, the technology each employs, and then bring this information together by providing a fundamental understanding of lightning.

It is important to understand that no individual component or combination of components will provide a warning system that is $100 \%$ effective. This report shows that by: 1) using a combination of components, 2) having an understanding of the information the components provide as well as their limitations, and 3) combining this information with a knowledge of lightning theory, we can provide a reasonable effective warning system.

\section{References}

${ }^{1}$ J. A. Chalmers, Atmospheric Electricity II, London, England, Pergamon Press, 1967, pp. 42-136.

${ }^{2}$ R. Markson, B. Anderson, and J. Govaert, "Comparison Between Field Mill and Corona Point Instrumentation at Kennedy Space Center," Proceedings of the 1989 International Conferences on Lightning and Static Electricity, University of Bath, England, September 26-28, 1989, pp. 2-7.

${ }^{3} \mathrm{R}$. Hasbrouck, Lightning-Understanding It and Protecting Systems from Its Effects, UCRL-53925 (Livermore, CA: Lawrence Livermore National Laboratory), April 1989, pp. 8-17.

${ }^{4}$ C. A. Scott, Lightning Detection and Sensing on the Nevada Test Site, National Oceanic and Atmospheric Administration (National Weather Service Nuclear Support Office), February 1990, pp. 2-3.

${ }^{5}$ M. A. Uman, Lightning, New York, McGraw-Hill, 1969, p. 8.

${ }^{6}$ E. R. Williams, R. E. Orville, "Intracloud Lightning as a Precursor to Thunderstorm Microburst," Proceedings of the 1988 International Aerospace and Ground Conference on Lightning and Static Electricity," Oklahoma City, Oklahoma, April 19-22, 1988, p. 454. 


\section{DISTRIBUTION:}

$\begin{array}{rll}100 & 2413 & \text { R. A. Smith } \\ 1 & 2701 & \text { G. L. West } \\ 1 & 2710 & \text { R. D. Bentley } \\ 1 & 2711 & \text { R. R. Beasley } \\ 1 & 2711 & \text { R. W. Phillips } \\ 1 & 2712 & \text { C. E. Smith } \\ 1 & 2713 & \text { K. J. Datz } \\ 1 & 2713 & \text { J. G. Dykes } \\ 1 & 2713 & \text { J. A. Enlow } \\ 1 & 2713 & \text { C. L. Girard }\end{array}$

12713

12713

$1 \quad 2732$

16321

17733

$1 \quad 7733$

1 8523-2

$5 \quad 7141$

$8 \quad 7613-2$

$3 \quad 7151$
D. S. Kessel

L. W. Lathrop W. D. Pregent

H. W. Church

A. M. Fine

D. Y. Joe Central Technical Files S. A. Landenberger Document Processing For DOE/OSTI

G. C. Claycomb 